\title{
PREPAREDNESS OF THE BHAKTI WIRATANTAMA ARMY HOSPITAL SEMARANG IN FACING COVID-19
}

\author{
Moh. Andi Fatkhurokhman'), Budi Hidayat ${ }^{2)}$ \\ 1)Hospital Administration Studies, Faculty of Public Health, \\ Universitas Indonesia, Depok, West Java, Indonesia \\ 2)Health Policy and Administration, Faculty of Public Health, \\ Universitas of Indonesia, Depok, West Java, Indonesia
}

\begin{abstract}
Background: On March 11, 2020, World Health Organization (WHO) established Covid-19 as a pandemic. Coronavirus is one of the large family of viruses that cause illnesses ranging from mild symptoms such as fever, coughing and shortness of breath, some of the case without symptoms. Coronavirus severe symptoms such as pneumonia, acute respiratory syndrome, kidney failure, and even can cause death. Coronavirus is transmitted between animals and humans. The average incubation period is about 6 to14 days. This study aimed to describe the preparedness of the Bhakti Wira Tantama Army Hospital Semarang, Central Java in facing the Covid-19 outbreak.

Subjects and Method: A mix method study was conducted at Bhakti Wira Tantama Army Hospital Semarang, Central Java. The process of organizing data in this study began with the literature study of health regulatory and laws in Indonesia. The instrument of this study was based on the Hospital Readiness checklist from WHO guidelines. The other data were collected using indepth interviews. The data then analyzed descriptively.

Results: Bhakti Wira Tantama Hospital was sufficient for a maximum capacity of 48 Covid-19 patients. In details, it showed that communication (87.49\%), continuity of essential health services and patient care (100\%), surge capacity (57.02\%), human resources (56.40\%), logistic and management of supplies including pharmaceuticals (51.51\%), surveillance early warning and monitoring (100\%), essential support services (95.23\%), case management (59.88\%), infection prevention and control (58.96\%), and laboratory services (53.85\%).

Conclusion: Bhakti Wira Tantama Army Hospital already have a very good level of preparedness in facing the Covid-19 pandemic.
\end{abstract}

Keywords: Covid-19, hospital readiness, world health organization

\section{Correspondence:}

Moh. Andi Fatkhurokhman. Hospital Administration Studies, Faculty of Public Health University of Indonesia, Depok, West Java, Indonesia. Email: andi.sptht@gmail.com. Mobile: 082135806088

\section{BACKGROUND}

The hospital is an important component of the health system which provides complete personal health services with inpatient, outpatient and emergency services as regulated in the Law Number 36 of 2009 concerning Health and Law Number 44 of 2009 concerning Hospitals.
According to Law Number 44 of 2009, the Hospital is a public service business unit with this type of organization that is capital, technology and labor intensive so that its management is not only limited to social affairs, but also socio-economic units that have social responsibility but in managing their finances. apply economic principles. This requires the hospital to be responsible

The $7^{\text {th }}$ International Conference on Public Health Solo, Indonesia, November 18-19, 2020 |114 https://doi.org/10.26911/the7thicph-FP.01.14 
for its performance in both service and financial aspects based on work standards and continuous quality improvement.

World Health Organization (WHO) in China Country Office reported a case of pneumonia in Wuhan City, Hubei Province, China on December 31, 2019. China identified a new type of pneumonia with the name coronavirus disease, which is shortened to COVID-19.

On January 7, 2020 and WHO designated COVID 19 as a Public Health Emergency of International Concern. On January 30,2020 . The increase in the number of COVID-19 cases continues to grow and is happening so fast that it has spread to hundreds of countries in the world. WHO officially designated the novel coronavirus disease in humans as Coronavirus Disease (COVID-19) on February 12, 2020 and on March 11, 2020, WHO officially designated COVID-19 as a global pandemic.

Lack of Hospital Preparedness in Indonesia, both from the availability of resources, facilities, facilities, infrastructure, and different knowledge of health workers on the COVID-19 protocol can pose risks and become obstacles to the safety of patients, medical personnel, non-medical personnel and the entire community. In an effort to tackle this outbreak, it is necessary to analyze the minimum preparedness and maximum isolation room capacity that must be provided by the Bhakti Wira Tamtama Army Hospital in the New Normal Era as one of the COVID-19 referral hospitals. This is what researchers are trying to answer.
SUBJECTS AND METHOD

\section{Study Design}

This was a qualitative study. This study requires proving objective phenomena and quantitative studies because it uses percentages, where after the data required through the WHO Hospital Readiness questionnaire is collected then classified according to a predetermined formulation and the results are in the form of a percentage, then the conclusions of the results in the form of a percentage value obtained from this calculation is described in the form of descriptive sentences according to predetermined categories. This study was carried out at the Bhakti Wira Tamtama Army Hospital, Semarang, Indonesia in July-September 2020.

\section{Study Process}

The instrument needed in this qualitative study was in-depth interview. The in-depth interview guide was included informant identity and a list of interview questions that adjust to the conditions and work situations to be studied and based on the Questionnaire Guidelines/ Checklist from the WHO Hospital Readiness. The tools that researchers use in the interview process were laptop, document, zoom meeting, writing tool, and WhatsApp.

Another instrument used for the quantitative was questionnaire sheet containing questions where the respondent / informant can provide answers by giving a checklist (V).

Then the percentage value obtained from the calculation results is described qualitatively. In order to obtain the results in the form of a qualitative analysis, the results of the calculation of this percentage are put into five predicate categories. 
The measurement results in the form of these five predicate categories will later describe the readiness of the Bhakti Wira Tamtama Army Hospital during the COVID-19 pandemic.

Primary data collection was done by in-depth interviews, questionnaires, literature studies, and document review. Data analysis was inductive in nature, the data collected consists of primary data and secondary data, the way primary data was collected by:

1. In-depth interviews by asking the informant's willingness to be interviewed according to existing topics

2. The interview was structured and informal so that researchers get the information needed

3. Researchers inform informant for a return interview if additional information is needed.

4. Hospital Readiness Checklist from WHO

Secondary Data Collection

1. Using questionnaires to obtain information

2. Literature studies to analyze data or information that researchers receive from informants, along with government regulations related to research

3. Document review where the researcher collects the required documents and data and then reviews them regularly deep so that it can support and increase confidence and proof of an event.

4. Documentation in the form of videos, photos, diagrams, pictures.

\section{Data Analysis}

The data collected were both quantitative and qualitative data from primary and secondary data sources as material for analysis, then classified, compiled, and tabulated data based on Hospital Readiness from WHO. From the data obtained, not all of the researchers have to put in the report, especially the data in the form of videos, images, text and language which are so complex and large that they need to be disaggregated. Qualitative research data analysis focuses on some of the data and ignores other parts. The data obtained were analyzed descriptively.

\section{RESULTS}

\section{Hospital Preparedness}

Hospital preparedness in pandemic disaster management will be demonstrated by a command management system or emergency management in the form of Standard Operating Procedures (SOP), including procedures for receiving victims and technical handling. The results showed that Bhakti Wira Tamtama Army Hospital already has SOP for handling disaster victims. In preparing the SOP, it involves the leadership, division heads, implementing staff and other health workers. Bhakti Wira Tamtama Army Hospital has also formed a COVID-19 Rapid Action Team in accordance with the Regulation of the Minister of Health of the Republic of Indonesia, a letter from the director of Bhakti Wira Tamtama Army Hospital, which has involved all health workers and medical personnel in Bhakti Wira Tamtama Army Hospital.

\section{Key Components of the Hospital Readiness checklist for Covid-19:}

\section{a. Communication}

Based on the research results, Bhakti Wira Tamtama Army Hospital already has excellent communication readiness in dealing with the COVID-19 pandemic with a result

The $7^{\text {th }}$ International Conference on Public Health Solo, Indonesia, November 18-19, 2020 |116 https://doi.org/10.26911/the7thicph-FP.01.14 
of (87.49) when compared to when Bhakti Wira Tamtama Army Hospital started. operates to open services against infectious diseases, namely the COVID-19 pandemic

\section{b. Continuity of Essential Health Services and Patient Care}

Based on the research results, Bhakti Wira Tamtama Army Hospital has had very good readiness since the beginning of the COVID-19 pandemic, namely in March 2020 in maintaining facilities, facilities and service infrastructure essential health during the New Normal and the new habit of COVID-19, with a yield of (100\%).

\section{c. Surge Capacity}

Based on the research results, Bhakti Wira Tamtama Army Hospital already has good Surge Capacity readiness to face the COVID-19 pandemic with a yield of (80.23\%). Services for COVID-19 patients at Bhakti Wira Tamtama Hospital were developed with special ICU facilities in isolation rooms, additional VIP isolation rooms, construction of parks with safety fences, installation of internet facilities and by the body, additional 16 beds, so that in July 2020 to 48 beds from the previous 32 beds. The results of this assessment state that there is an increase in the performance and quality of service at Bhakti Wira Tamtama Army Hospital in the face of the COVID-19 pandemic.

\section{d. Human Resources}

Based on the results of research, Bhakti Wira Tamtama Army Hospital already has good human resource readiness in facing the COVID-19 pandemic with a yield of (74.58\%). Bhakti Wira Tamtama Army Hospital during the pandemic in May-June 2020 was able to accommodate 32 COVID19 patients and in July-September 2020 it was able to accommodate 48 COVID-19 patients. Bhakti Wira Tamtama Army Hospital Hospital's human resources have been trained based on guidelines and instructions from WHO and the ministry of health in handling COVID-19 patients since the beginning of the Pandemic, namely in March 2020.

\section{e. Logistics and Management of Supplies Including Pharmaceuti- cals}

Based on the research results, Bhakti Wira Tamtama Army Hospital already has very good logistics and pharmaceutical readiness. good in facing the COVID-19 pandemic with the acquisition of results of (98.81\%).

\section{f. Surveillance Early Warning and Monitoring}

Based on the research results, Bhakti Wira Tamtama Army Hospital already has excellent surveillance readiness during the New Normal and New Habits in dealing with the COVID-19 pandemic compared to the beginning of the pandemic in March 2020 with the acquisition of results of (100\%).

\section{g. Essential Support Services}

Based on the research results, Bhakti Wira Tamtama Army Hospital has had excellent support service readiness since the beginning to face the COVID-19 pandemic with a result of (98.96\%).

\section{h. Case Management}

Based on the results of research, Bhakti Wira Tamtama Army Hospital already has a very good Case Management in dealing with the COVID-19 pandemic with a result of (97.61\%).

\section{i. Infection Prevention and Control (PPI)}

Based on the results of research, Bhakti Wira Tamtama Army Hospital already has excellent PPI readiness during the New

The $7^{\text {th }}$ International Conference on Public Health Solo, Indonesia, November 18-19, $2020 \mid 117$ https://doi.org/10.26911/the7thicph-FP.01.14 
Normal and New Habits in the face of the COVID-19 pandemic with $99.55 \%$ results.

\section{j. Laboratory Services}

Based on the research results, Bhakti Wira Tamtama Army Hospital already has good laboratory readiness in dealing with the COVID-19 pandemic with a result of (100\%) for the maximum capacity for the isolation room of 32 COVID-19 patients.

\section{DISCUSSION}

From the results of this study, the Readiness and Preparedness of Bhakti Wira Tamtama Army Hospital during the pandemic in March-June 2020 was sufficient for the maximum capacity of the isolation room for Covid-19 patients as many as 48 patients with the Incident Management System as a whole the results were very good where Communication entered at a very good level, namely (87.49\%), Continuity of Essential Health Services and Patient Care entered at a very good level judged by the facilities, facilities, essential service infrastructure, namely (100\%), Surge Capacity entered at a very good level namely (80.23\%), Human Resources entered at a good level, namely (74.58\%), Logistics and Management of Supplies Including Pharmaceuticals entered at a very good level, namely (98.81\%), Surveillance Early Warning and Monitoring entered at a very good level, namely (100\%), Essential Support Services entered at a very good level, namely (98.96)\%, Case Management t entered at a very good level, namely (97.61\%), Infection Prevention and Control entered at a very good level of (99.55\%), and Laboratory Services entered at a quite very good level of (100\%). Although improvements and strengthening of services, facilities, facilities, infrastructure and policies in the hospital are still needed.

\section{SUGGESTION}

1. The hospital needs to plan for additional negative pressure isolation rooms to anticipate mass casualties.

2. Hospitals need to compile existing HR plans and recruit health personnel and volunteers from the community if at any time there is a rapid spike in $\mathrm{C}-19$ patients and their health workers are infected too.

\section{REFERENCE}

Bhakti Wira Tamtama Hospital (2020). Standard operational procedure COVID-19. Semarang: RS BWT.

Bhakti Wira Tamtama Hospital (2020). Kesiapsiagaan Rumah Sakit Semarang: RS BWT.

World Health Organization (2020). Global surveillance for human infection with novel coronavirus. https://www.who.int/publications-detail/globalsurveillance-for-human-infectionwith-novel-coronavirus-(2019-ncov). World Health Organization (2020). Hospital readiness checklist for COVID-19. http://www.emro.who.int/images/stories/coronavirus/documents/hos pital_readiness_checklist_for_covid_ 19.pdf. 